\title{
El impacto de la crisis económica en el proceso judicial social: la nueva ley de la jurisdicción social (2011) y sus posteriores reformas en 2012
}

\author{
Miguel Ángel Purcalla Bonilla \\ Magistrado de lo Social y Profesor Titular de Universidad \\ (en exedencia voluntaria) \\ ma.purcalla@poderjudicial.es
}

Resumen: El trabajo aborda los principales cambios que la nueva ley procesal laboral (LRJS - Ley 36/2011-) ba introducido en la práctica en las demandas presentadas ante los juzgados y tribunales laborales. Agilidad, celeridad, menor coste y otros objetivos se plantearon en su versión inicial (noviembre de 2011), pero muy pronto han debido adaptarse a los cambios normativos (en especial, en el Estatuto de los Trabajadores) que la crisis económica ha provocado durante 2012. En la actualidad, con todo, los cambios normativos que se explican en estas páginas van de la mano de un incremento de litigios, fruto de la crisis económica, que, lejos de agilizar realmente el proceso laboral, está saturando a los juzgados de lo social, aunque estos, pese a los recortes (bumanos y económicos) que padecen, tratan de sobrellevar esa ingente carga en aras a brindar a los ciudadanos la mejor tutela posible de sus derechos laborales $y$ de Seguridad Social.

Palabras clave: jurisdicción social, reformas procesales, crisis económica.

Abstract: This study focuses on the main changes that the new labour law (LRJS Law 36/2011-) has made to the practice of bringing lawsuits before labour courts and tribunals. The aim of the initial version (November 2011) was to make the process agile, quick and economical, among other things, but very soon this aim bad to adapt to the changes in the law (and particularly in the Spanish Workers' Statute) that the economic crisis caused in 2012. At present, the changes in the law that will 
Miguel Ángel Purcalla Bonilla

be discussed here have been accompanied by an increase in litigation - the result of the economic crisis - which, far from making actions under labour law more agile, is saturating the social courts (the Spanish courts that specialize in labour law). Despite the cuts in buman and economic resources, these courts put up with the ever increasing workload in an attempt to protect citizens' labour and social security rights as best they can.

Keywords: social jurisdiction, procedural reforms, economic crisis. 


\section{Los motivos de la nueva ley procesal laboral}

El 11 de octubre de 2011 se publicó en el Boletín Oficial del Estado la Ley 36/2011, de 10 de octubre, reguladora de la jurisdicción social (en adelante, LRJS). Esta norma ha venido a derogar $y$, por consiguiente, a sustituir desde el 11 de diciembre de 2011 (que es su «fecha de entrada en vigor», esto es, la fecha de su aplicación práctica, con excepción de las competencias relativas a la Ley de Dependencia - Ley 39/2006-, que quedan pospuestas hasta 2014) a la anterior Ley de Procedimiento Laboral (LPL), aprobada mediante Real Decreto Legislativo 2/1995, de 7 de abril.

La LRJS mantiene la estructura de la LPL, su numeración y la mayor parte de su articulado, si bien diversos cambios respecto de la anterior ley son de importancia. Así, la LRJS se inicia con un preámbulo en el que pretende explicar las dos razones o motivos para su aprobación:

La actualización del proceso en aras de una mayor eficacia y agilidad, impulsando así una más adecuada y efectiva tutela de los derechos de trabajadores y beneficiarios de la Seguridad Social.

La atribución al orden social («jueces laborales») del conocimiento de la diversidad de materias que se incluyen en el ámbito laboral - evitando así la dispersión de algunas de ellas en otras jurisdicciones como la civil o la contencioso-administrativa y la correspondiente inseguridad que ello había venido generando-, con especial atención a los daños derivados de los accidentes de trabajo y a la impugnación de las resoluciones recaidas en los expedientes de regulación de empleo. De este modo, unidad jurisdiccional, certeza jurídica, economía procesal y rapidez de la respuesta, con disminución de los costes de litigación, son los objetivos que pretende la Ley reguladora de la jurisdicción social, que hace también una apuesta decidida por los procedimientos extrajudiciales de composición de los conflictos laborales, señaladamente por la mediación y los laudos arbitrales, como instrumentos de contención de la litigiosidad social.

Dicho a vuelapluma, la estructura de la LRJS es sencilla: en el libro primero (artículos $1 \mathrm{al} 75$ ) se tratan cuestiones generales relativas a la potestad jurisdiccional, las partes procesales, la acumulación de acciones, procesos y recursos, los actos procesales, la evitación del proceso y los principios y deberes procesales; el libro segundo regula el proceso ordinario y cada una de las modalidades procesales o «procesos especiales» - esto es, procesos que presentan diferencias en su tramitación con el común o general- (artículos 76 al 185); el libro tercero se ocupa de los medios de impugnación o «recursos» (artículos 186 al 236); finalmente, el libro cuarto se ocupa de la ejecución de sentencias - esto es, de cómo se puede garantizar y de qué manera y forma el cumplimiento eficaz del contenido 
de las sentencias judiciales, de los acuerdos de conciliación o de los laudos arbitrales de contenido «laboral»- (artículos 237 al 305). Además, cuenta con una serie de disposiciones adicionales (2), finales (7) y transitorias (5), así como con una disposición derogatoria única (que deroga expresamente en su integridad la LPL y «cuantas disposiciones de igual o inferior rango se opongan a la nueva ley», a modo de cláusula de estilo habitual de derogación «tácita» o, como dicen también los juristas, «abrogación»).

Ahora bien, como era de prever por los cambios políticos y normativos (no es preciso estar muy avezado en Derecho para saber que la norma siempre va detrás - o, mejor, después - de la realidad social, pero también que la «ideología» muchas veces influye en el contenido de las normas, que, por lo tanto, están sujetas a los vaivenes políticos y económicos - hoy, con la crisis como telón de fondo que motiva reformas a modo de pretendido «bálsamo de fierabrás»-), la nueva norma apenas ha durado sin modificaciones. En efecto, si, como se ha dicho, entró en vigor desde el día 11 de diciembre de 2011, ya ha sido parcialmente modificada (para su adecuación a las reformas laborales de 2012) por el Real Decreto-Ley 3/2012, de 10 de febrero, de medidas urgentes para la reforma del mercado laboral (que entró en vigor el 12 de febrero de 2012), sin casi tiempo, por cierto, para el estreno de alguna de las «novedades» de 2011, y después por la Ley 3/2012, de 6 de julio (vigente desde el 8 de julio de 2012), que convalida, como paso político y jurídico habitual, el RDLey 3/2012 de medidas urgentes para la reforma del mercado laboral. En conclusión, los embates de la crisis y la ola de reformas han afectado no solo a las normas «laborales» en sentido estricto (Estatuto de los Trabajadores, en especial, para que nos entendamos), sino también lógicamente a la norma «procesal», que no deja de ser el complemento a aquella normativa por cuanto brinda tutela «judicial» a los derechos laborales, esto es, que se constituye como el cauce o vía (el «proceso») para dar utilidad y «eficacia» social a la norma jurídico-laboral y de protección social («Seguridad Social»y «Asistencia Social»).

\section{Primer objetivo: la ampliación de competencias en el orden social}

La LRJS atribuye íntegramente al orden jurisdiccional laboral todas aquellas materias laborales y de protección social, a excepción de los actos de administración y gestión recaudatoria de la Seguridad Social (actos que lleva a cabo la Tesorería General de la Seguridad Social). Se racionaliza, por lo tanto (o, cuando menos, se intenta), 
la distribución competencial entre los órdenes civil, contencioso-administrativo y social, concentrándose en este último, por su mayor especialización, el conocimiento de todas las cuestiones que directamente o por especial conexión sean de índole laboral. En concreto, la jurisdicción laboral (juzgados de lo social - JS, salas sociales de los tribunales superiores de justicia [TSJ], del Tribunal Supremo [TS] y de la Audiencia Nacional [AN] -) resulta ahora competente de forma «novedosa» para los temas que se exponen a continuación.

\subsection{Accidentes de trabajo y prevención de riesgos laborales}

Con el objetivo de crear un ámbito unitario de tutela jurisdiccional para el resarcimiento integral del daño causado y dotar de una mayor protección a los trabajadores en casos de siniestralidad laboral, el orden social de la jurisdicción es competente para conocer en materia de accidentes de trabajo y enfermedades profesionales, incluida la acción directa contra la aseguradora, de forma que todas las cuestiones litigiosas derivadas de tales contingencias se diluciden en este orden, y acabar así con el llamado «peregrinaje jurisdiccional» existente hasta el momento. Ese fenómeno consistía en lo siguiente: ante un accidente de trabajo, el acta de inspección debía impugnarse ante la jurisdicción contenciosa y las prestaciones de Seguridad Social (incapacidad, viudedad, orfandad, etc.) y recargo de estas (art. 123 LGSS: de un 30 $\%$ a un $50 \%$ y a cargo del empresario o empresarios infractores) se dirimían ante la jurisdicción social. El Tribunal Constitucional tuvo que recordar en reiteradas ocasiones que el derecho fundamental a la tutela judicial podía resultar vulnerado por aquel «peregrinaje» (SSTC 71/2001 y 154/2004); que la efectividad de dicho derecho fundamental y las exigencias objetivas del principio de seguridad jurídica impuestas a todos los órganos del Estado son incompatibles con la existencia de pronunciamientos contradictorios firmes (lo que supone, sin duda, el «ridículo» de Derecho, amén de una clara inseguridad jurídica) sobre unos mismos hechos litigiosos (SSTC 158/1985, 70/1989, 190/1999, 151/2001, 34/2003, 16/2008, $117 / 2009,192 / 2009$ y 21/2011); y que es obligación de jueces y tribunales señalar el orden jurisdiccional competente (art. 9.6 LOPJ).

Sin perjuicio de las competencias de la Inspección de Trabajo (que también interviene en el proceso laboral, según se va a ver), el orden social de la jurisdicción asume también la facultad de garantizar el cumplimiento de las obligaciones legales y «convencionales» (convenios, pactos y acuerdos colectivos) en materia de prevención de riesgos laborales tanto frente al empresario como frente a otros sujetos responsables (contratistas, fabricantes, importadores y suministradores de maquinaria o productos, aseguradoras, etc.). 
Especialmente importante es señalar que los empleados públicos (funcionarios, personal estatutario - sanitario- y personal laboral de las administraciones públicas) podrán ejercer sus acciones en esta materia de riesgos laborales (en caso de mobbing como riesgo psicosocial, por ejemplo) ante la jurisdicción social, en igualdad de condiciones con los trabajadores por cuenta ajena («laborales») de las empresas privadas. Es un gran avance, pues hasta la nueva LRJS debían acudir ante la jurisdicción contenciosa, más lenta que la social (cuando menos y tradicionalmente, aunque la crisis y la saturación de trabajo está igualando los ritmos lentos) y más cara (no existe en la contenciosa beneficio de justicia gratuita para el empleado público) y menos especializada que la laboral, claro es, en temas de problemática sobre condiciones de trabajo.

La LRJS convierte, así, al juez laboral en el «juez natural» de los daños en el trabajo y, en concreto, de los derivados de accidentes de trabajo y enfermedades profesionales. Además, atribuye competencia a la jurisdicción social para enjuiciar a «todos los sujetos», la entidad aseguradora incluida - y no solo al empleador o empresario o a los empresarios ligados por relaciones de contratación o subcontratación legalmente responsables-, que concurran a la producción de daños al trabajador y todas «las acciones» por los causados, se basen en normas laborales o en normas civiles y sean imputables los daños a incumplimientos laborales o a incumplimientos ajenos al contrato de trabajo, siempre que se hayan producido «en el marco laboral o en conexión directa con el mismo». Los trabajadores o sus herederos, en suma, ya no tienen que acudir al orden civil ni impugnar ante la jurisdicción contencioso-administrativa las resoluciones dictadas por las administraciones laborales en el ejercicio de su potestad sancionadora, pues en la jurisdicción social podrán obtener «el resarcimiento integral del daño causado». Esa es la intención de la nueva ley, al menos.

\subsection{Dependencia y prestaciones de Seguridad Social}

Junto a la posibilidad de reclamar «pensiones» (de jubilación, por ejemplo, contra el Instituto Nacional de la Seguridad Social, impugnando sus resoluciones), debe señalarse que la valoración, el reconocimiento y la calificación del grado de discapacidad (que en la práctica ya se impugnan ante la jurisdicción social), así como las prestaciones derivadas de la Ley 39/2006, de 14 de diciembre, sobre promoción de la autonomía personal y atención a las personas en situación de dependencia, son materias que corresponden al orden social (aunque estas segundas diferidas hasta 2014). Igualmente, el artículo 2.o) de la LRJS precisa la competencia del orden social para conocer de la prestación por cese de actividad («pseudodesempleo») de los trabajadores por cuenta propia. 


\subsection{Intermediación laboral}

La jurisdicción laboral es competente para conocer sobre los conflictos que se planteen entre los trabajadores y las agencias de colocación, los servicios públicos de empleo (estatal y autonómicos) y otras entidades colaboradoras (antenas de empleo, bolsas de trabajo, ETT, etc.). Del mismo modo, las controversias entre estas entidades colaboradoras y los servicios públicos de empleo serán también competencia de la jurisdicción social.

\subsection{Expedientes de regulación de empleo (ERE)}

Se residencian en el orden jurisdiccional social los recursos contra las resoluciones de la autoridad laboral recaídas en todo tipo de expediente de regulación de empleo (despido colectivo, suspensión temporal de contratos de trabajo y reducción de jornada). No obstante, para la impugnación de los actos administrativos dictados en un ERE con anterioridad a la entrada en vigor de la Ley (11 de diciembre de 2011) seguirá siendo competente la jurisdicción contencioso-administrativa.

Una cuestión práctica de interés: un «despido colectivo» (véase art. 51 del Estatuto de los Trabajadores) debe ser impugnado, como regla general (salvo las «prioridades de permanencia», es decir, en un despido colectivo de parte de la plantilla, hay trabajadores que tienen preferencia para no ser despedidos, ya sea por ley - representantes de los trabajadores - o por convenio colectivo - familias numerosas, discapacitados, veteranos, etc.-), ante la Sala Social de los TSJ (art. 124 LRJS) en primer lugar o «instancia», Por el contrario, un ERE de suspensión de contratos o reducción de jornada de una empresa de Madrid, por ejemplo, debe ser impugnado ante el Juzgado de lo Social de Madrid en primera «instancia».

\subsection{Actos de las administraciones públicas}

Son también impugnables ante la jurisdicción social los actos de las administraciones públicas recaídos en materia laboral y sindical, incluidos los que se dicten en el ejercicio de su potestad sancionadora (actuación de la Inspección de Trabajo y Seguridad Social) y aquellos dictados en materia de Seguridad Social, a excepción de los actos dictados en materia de gestión recaudatoria y encuadramiento. En definitiva, ahora es competencia del orden jurisdiccional social la impugnación de sanciones en materia laboral y de Seguridad Social. 
Si los actos impugnables son dictados por el Consejo de Ministros (depende del importe de la multa y del tipo de sanción e infracción), la competencia del orden jurisdiccional social recaerá en única instancia en la Sala de lo Social del Tribunal Supremo, contra cuya sentencia no cabe recurso.

\subsection{Derechos fundamentales}

Corresponde al orden social el conocimiento de cualquier vulneración de los derechos fundamentales y libertades públicas por parte del empresario o terceros vinculados a este por cualquier título, mencionándose expresamente la probibición del acoso y la discriminación. Y en esta materia, la LRJS ha introducido facultades concretas del juez de lo social, modificando la modalidad procesal de tutela de derechos fundamentales e introduciendo medidas cautelares ante situaciones de acoso o discriminación, sobre las cuales volveremos más adelante.

\section{Segundo objetivo: un proceso laboral más ágil, rapido y moderno (y con menos costes)}

La LRJS pretende adaptarse a los cambios que se introdujeron en la LEC (Ley de Enjuiciamiento Civil) en el año 2011 y aprovechar las potencialidades que ofrece la nueva oficina judicial, eliminando trámites superfluos e integrando las nuevas tecnologías para conseguir reducir los tiempos de tramitación.

\subsection{Nuevas tecnologías: hacia dónde vamos}

En las disposiciones relativas a las actuaciones procesales se hace expresa mención a su acceso telemático, y en aquellas que versan sobre los actos de comunicación se hace referencia a la posibilidad de que estos se lleven a cabo mediante fax o correo electrónico, lo que sin duda facilitará la labor de los letrados y graduados sociales colegiados. A tales efectos, se establece expresamente que en la demanda deberán indicarse datos como el teléfono, el fax y la dirección electrónica — si se dispone de ellos - para poder practicar comunicaciones a través de estos medios.

La utilización de medios telemáticos e informáticos a efectos de comunicación con los tribunales (en realidad, el personal de gestión del juzgado - agentes, tramitadores, «oficiales» y secretario-) y entre las partes es necesaria para «reducir» el papel y aligerar notificaciones y requerimientos, y será, sin duda y 
de implantarse con los años (que nadie espere que se haga ya y pronto), un gran avance. Ahora bien, el legislador está presuponiendo algo que todavía no existe en la realidad judicial española: el expediente electrónico, que en la práctica sigue siendo un expediente «en papel».

\subsection{Alternativas al proceso judicial}

Se trata de potenciar la mediación previa, fomentando la evitación del proceso judicial. Para ello, se establece expresamente que acudir de forma voluntaria a un trámite de conciliación o mediación, no siendo estas preceptivas (en cuanto a alcanzar un acuerdo), suspenderá los plazos de caducidad e interrumpirá los de prescripción, en la medida en que por la naturaleza de la pretensión el acuerdo que pudiera alcanzarse pudiera tener eficacia jurídica.

Del mismo modo, se clarifica la posibilidad de que las partes pueden comparecer ante la oficina judicial a los efectos de celebrar la correspondiente conciliación, en fecha anterior a la fijada para los actos de conciliación y juicio o en el mismo día.

Por último, también se aclara de forma expresa la posibilidad de que el magistrado-juez de lo social realice un último intento de avenencia entre las partes, pudiéndose alcanzar la conciliación ante este en el caso de que no se hubiera conseguido ante el secretario judicial e incluso instar a las partes, una vez practicada la prueba y antes de la formulación de conclusiones, a los mismos efectos.

\subsection{Acumulación}

Una de las medidas más relevantes para conseguir esa agilización procesal radica en fomentar la acumulación de acciones («en la misma demanda») y de procedimientos («autos» o expedientes distintos ante el mismo juzgado y resueltos a la vez). A tales efectos, son varias las modificaciones que se plantean en la LRJS respecto de la LPL, siendo las siguientes las más destacables:

A) En materia de accidentes de trabajo y enfermedades profesionales, se podrán acumular todas las pretensiones de resarcimiento de daños y perjuicios derivados de un mismo hecho, incluyendo las mejoras voluntarias (por ejemplo, complemento del subsidio de incapacidad temporal por enfermedad común hasta el $100 \%$ —dado que por Ley solo se cubre el $60 \%$ o el $75 \%$-).

B) Acumular a la acción de despido la reclamación de la liquidación de haberes («finiquito») derivada del propio acto extintivo. No obstante, se precisa por 
la Ley que, si la propia complejidad de los conceptos reclamados (por ejemplo, opciones sobre acciones, retribuciones variables, etc.) conllevara una dilación indeseada del proceso de despido, el juez podrá decidir que la reclamación de cantidad se tramite en un proceso separado ante el mismo juzgado.

C) Posibilidad de que el autónomo dependiente (TRADE) acumule a la acción principal de despido (si pretende que se declare la naturaleza laboral de la relación, que se había trabado como mercantil o civil) la derivada contra la decisión del cliente de extinguir la relación, y viceversa.

\subsection{Proceso monitorio}

En esta línea de economía de trámites procesales, se crea un nuevo proceso monitorio, que supone otra de las novedades más relevantes en el proceso laboral y que pretende descargar la agenda de los señalamientos de los juzgados de lo social, con la finalidad de agilizar el cobro de los importes reclamados, al no ser necesaria la citación a juicio.

A través de este proceso, el trabajador puede reclamar contra el empresario que no se encuentre en concurso cantidades inferiores a 6.000 euros, siempre que la deuda esté determinada y sea líquida (es decir, que sea clara y no discutida). Para ello, el trabajador deberá acreditar junto con la petición inicial la existencia de la relación laboral y de la cuantía adeudada, así como facilitar los datos de localización y comunicación tanto del demandante como del demandado. El juzgado requerirá al demandado — dando traslado de este requerimiento al FOGASApara que en el plazo de 10 días abone la deuda o se oponga total o parcialmente a esta. De no cumplirse el requerimiento en uno u otro sentido, se despachará ejecución. De existir oposición, se dará un plazo de cuatro días al demandante para que interponga la correspondiente demanda, en cuyo caso se señalará fecha para conciliación y juicio, que se seguirá como «procedimiento ordinario».

En consecuencia, las características de este nuevo proceso monitorio laboral rápido son:

- La reclamación solo se atribuye al trabajador frente al empresario.

- El empresario demandado no ha de encontrarse declarado en situación de concurso.

- Se limita a reclamación de cantidades determinadas, vencidas y exigibles, no superiores a 6.000 euros.

+ Se excluye la comunicación edictal. 
- Expresamente, la Ley excluye las reclamaciones de carácter colectivo que pudiera presentar la representación de los trabajadores y las reclamaciones contra entidades gestoras y colaboradoras de la Seguridad Social.

\subsection{Reclamación al Estado de salarios de tramitaciónł una reforma para el ahorro}

Se modifica por la LRJS el régimen de reclamación al Estado del abono de los salarios de tramitación en los casos de despido declarado nulo o improcedente por sentencia judicial firme. En concreto, se indica que los salarios de tramitación que se devenguen desde la presentación de la demanda hasta la sentencia del juzgado que por primera vez declare la improcedencia, siempre que hayan pasado más de 90 días hábiles (es decir, el Estado corre a cargo desde el día 91 —antes, con la LPL, desde el día 61-), corren a cuenta del Estado previa reclamación del empresario que los haya abonado, una vez firme la sentencia y siempre que se reclame en el plazo de un año desde su abono.

\subsection{La desaparición del «despido exprés»y el fin de los salarios de tramitación de un despido (salvo readmisión del trabajador)}

Hasta la reforma que entró en vigor el 12 de febrero de 2012 (RDLey 3/2012), el empresario que reconocía la improcedencia del despido y ponía a disposición del trabajador despedido la indemnización correspondiente a 45 días de salario por año trabajado - depositándola en el Juzgado de lo Social y comunicándoselo al trabajador - paralizaba lo salarios de tramitación (que son aquellos que se generan desde el despido hasta la notificación de la sentencia que declara la improcedencia). Si el depósito se realizaba en las 48 horas siguientes al despido, no se devengaban salarios de tramitación; de efectuarse pasadas dichas 48 horas, los salarios devengados eran los que mediaban entre la fecha del despido y la del depósito. Esta posibilidad de reconocimiento de la improcedencia desapareció con la reforma operada vía RDL 3/2012, del mismo modo que han desaparecido los salarios de tramitación (para los despidos posteriores al 12 de febrero de 2012, no para los de fecha anterior aunque la sentencia judicial se dicte después de dicha fecha), salvo que el empresario opte por la readmisión.

Sobre el ofrecimiento de reconocimiento de la improcedencia y entrega de la indemnización, la STS de 18 de diciembre de 2009 señaló que, aun cuando el 
trabajador percibiera la indemnización ofrecida, su disconformidad con el despido y la interposición de la ulterior demanda judicial permite que en el litigio pueda alterarse la postura empresarial (esto es, que defienda la procedencia) porque la empresa no queda vinculada por una oferta transaccional no aceptada por el trabajador.

De este modo, en la actualidad (septiembre de 2012) solo proceden salarios de tramitación para despidos posteriores al 12 de febrero 2012 cuando el despido: a) sea declarado nulo; b) sea declarado improcedente si la empresa opta por la readmisión; y c) sea declarado improcedente y afecte a un representante legal de los trabajadores (comité de empresa, delegado de personal, delegado de prevención) o a un delegado sindical, a quien corresponde siempre la opción entre readmisión o indemnización y en ambos casos tiene derecho a salarios de tramitación.

\subsection{Señalamientos}

Se reduce a 10 dias el periodo que debe mediar entre la citación y la fecha de la efectiva celebración de los actos de conciliación y juicio, salvo en los casos en que se establezca otro plazo en la LRJS o en aquellos en que se deba fijar nuevo señalamiento tras una suspensión de la vista (por ejemplo, por incomparecencia por razones de salud acreditadas de una de las partes, o por petición del demandante para ampliar la demanda contra otra empresa o, por ejemplo, contra una aseguradora o mutua).

El tema de las fechas en la agenda judicial se concreta con ciertos cambios como, por ejemplo, que los litigios que se refieran a las mismas partes y que no puedan ser acumulados se señalarán, si es posible, en el mismo día. Claro, buena voluntad hay, pero otra cosa es la realidad actual de los JS, que impide con frecuencia llevar a cabo la benévola previsión legal.

\subsection{Conciliación administrativa previa: ampliación de los casos exceptuados}

La conciliación previa a la vía judicial (ante el órgano administrativo correspondiente) sigue siendo requisito preprocesal, pero se amplían en la LRJS los supuestos exceptuados, como son los procesos de anulación de los laudos, la impugnación de acuerdos en conciliación, mediación o transacciones. Novedad importante es la previsión de que se reanude la caducidad suspendida a los 15 
días hábiles, excluyendo del cómputo los sábados (art. 65.1 LRJS), y que, para el caso de incomparecencia injustificada a la conciliación, se establezca que se impondrán por el juez las costas, que incluyen los honorarios del letrado o graduado social hasta 600 euros (art. 66.3 LRJS) si la sentencia acepta los términos esenciales de esta («pretensión»).

\section{Tercer objetivo: mayor intervención del fondo de garantía salarial (FOGASA)}

La LRJS altera sustancialmente el artículo 23 de la LPL y refuerza la presencia en juicio del FOGASA. Las modificaciones más relevantes a este respecto pueden resumirse como sigue: se clarifica la intervención del FOGASA en los procedimientos que se insten al amparo de lo previsto en el artículo 33.8 del ET; se establece la obligación de notificación al FOGASA de la admisión a trámite de la demanda, señalamiento o incidente; se aclaran sus facultades (respecto de la formulación de excepciones, prueba y recursos) cuando actúe ante la jurisdicción social; se establece su legitimación en procedimientos arbitrales y en la impugnación de laudos, conciliaciones, allanamientos y transacciones, tanto administrativas como judiciales; se prevé la obligación del FOGASA de alegar todos los motivos de oposición a la demanda y los efectos de su acogimiento, con especial mención a las cuestiones de prescripción, caducidad e interrupción de la prescripción que pudieran afectarle; se establece igualmente su vinculación a la sentencia firme de haber sido emplazado en el pleito, la presunción de certeza de sus resoluciones y su deber de colaboración en el pleito mediante la aportación del expediente administrativo.

¿Qué sucede en la práctica? Sencillo: el FOGASA está desbordado ante el aluvión de materias en la que es citado a juicio y sus letrados escasamente comparecen a los juicios. Eso sí, el día que pueden personarse ante un JS, se quedan en todos los procedimientos de ese día y JS.

\section{Cuarto objetivo: mejora de los actos preparatorios y las diligencias preliminares}

Se posibilita, a quien pretenda solicitar del Juzgado de lo Social la petición de las oportunas diligencias para esclarecer la determinación de los socios, partícipes, gestores o miembros de una entidad sin personalidad, la determinación del em- 
presario y del grupo empresarial o la de las personas que hayan concurrido a la producción del daño y la cobertura de su riesgo.

La Inspección de Trabajo, así como la autoridad laboral, podrán solicitar del juzgado la autorización correspondiente para inspeccionar el centro de trabajo cuando este coincida con el domicilio del afectado y concurra su oposición, toda vez que la jurisdicción social pudiera conocer posteriormente del procedimiento derivado de dicha inspección. Si la realización de la diligencia solicitada puede afectar a la intimidad personal u a otro derecho fundamental y no consta la aceptación del afectado, aquella podrá acordarse con las garantías previstas en el artículo 90 de la LRJS.

Ejemplo práctico: se posibilita al empresario que pretenda demandar al trabajador por daños — por ejemplo, derivados de competencia desleal- solicitar al juzgado que autorice la inspección de su ordenador y su correspondencia electrónica - de tenerse la sospecha fundada de la utilización de tales medios para llevar a cabo dicho incumplimiento-, evitándose así, de ser estimada la solicitud, posteriores problemas de ilicitud de pruebas por vulneración de derechos fundamentales.

\section{Quinto objetivo: cambios sobre las pruebas 6.1 Novedades sobre la admisión y práctica de la prueba}

En relación con la admisión de las pruebas a practicar durante el acto del juicio, el artículo 87.2 de la LRJS se remite expresamente al artículo 299 de la LEC: el juez de lo social queda facultado para determinar la naturaleza y clase del medio de prueba propuesto de no haberse hecho de forma correcta. Igualmente, y en relación con un planteamiento incorrecto o incompleto de las tesis de las partes o por derivarse de las pretensiones un preceptivo pronunciamiento judicial, el juez de lo social podrá recabar ulteriores alegaciones de las partes, lo que podrán realizar incluso finalizado el acto de juicio, mediante escrito que será remitido preferiblemente por medios telemáticos o informáticos.

Por otro lado, se reduce de 10 a 5 días hábiles previos a la vista el plazo para solicitar la práctica de pruebas que exijan diligencias de citación o requerimiento. Un nuevo intento de «agilizar» el proceso, como se ve. 


\subsection{Prueba anticipada}

Se explicita ahora en el artículo 82.4 de la LRJS lo que ya venía siendo una práctica extendida en los órganos judiciales: el intercambio entre las partes previo al acto de juicio - con al menos cinco días de antelación a este- de las pruebas documentales o periciales complejas y voluminosas, a fin de no dilatar con su revisión el acto de la vista.

A su vez, el artículo 78.2 de la LRJS admite la práctica de la prueba anticipada, siempre que no suponga la suspensión del acto de la vista. A tales efectos se remite expresamente a lo establecido en la LEC, en concreto, en sus artículos 293 a 297 y 298.1, en los que, entre otras cuestiones, se regulan medidas de aseguramiento de la prueba.

\subsection{Carga probatoria}

Por lo que se refiere a la carga probatoria, en especial a la inversión de la carga de la prueba, se destacan las siguientes novedades: a) en materia de accidentes de trabajo y enfermedades profesionales, los responsables de seguridad y salud laboral deberán probar la adopción de las medidas para prevenir o evitar el riesgo, no pudiendo apreciarse como elemento exonerador de la responsabilidad la culpa no temeraria del trabajador; b) se añade expresamente que, en las situaciones de acoso y cualquier otra vulneración de derechos fundamentales y libertades públicas, corresponderá al empresario la acreditación de una justificación objetiva y razonable de la medida adoptada (lo que en Derecho se llama «carga de la prueba»).

Es igualmente de interés destacar las facultades que en el artículo 90 de la LRJS se trasladan al juez de lo social para que este garantice el respeto a los derechos fundamentales en relación con la admisión y práctica de la prueba. Así, se establece expresamente la inadmisión de aquellas pruebas que tuvieran su origen o se hubieran obtenido, directa o indirectamente, vulnerando derechos fundamentales, lo que podrá apreciarse de oficio o a instancia de parte. El juez de lo social queda asimismo facultado para autorizar el acceso a documentos o archivos que puedan afectar a la intimidad personal $u$ otro derecho fundamental, tras la ponderación de los intereses afectados según el juicio de proporcionalidad, estableciendo medidas adecuadas para dicho acceso, conservación, aportación al proceso y entrega de copias a las partes. En el mismo sentido, y por lo que se refiere a los reconocimientos clínicos o médicos, de no mediar consentimiento del afectado, el juez de lo social podrá autorizar la práctica de las correspondientes pruebas médicas o psicológicas, arbitrando medidas que garanticen la confidencialidad de 
los datos del afectado. Por último, se arbitra la adecuada garantía de los intereses que pudieran verse afectados si de la admisión de esas pruebas se aportaran datos innecesarios para el proceso o que pudieran considerarse desproporcionados.

\subsection{Interrogatorio de las partes}

La prueba de interrogatorio de las partes, en el caso de personas jurídicas, deberá practicarse en la persona que conozca directamente los hechos, pudiendo el solicitante de la prueba proponer, previa debida justificación, a la persona que deba someterse a dicho interrogatorio. Además, el juez podrá acordar que el interrogado (administrador, gerente o directivo) declare como testigo ( $y$ no como parte) en función de su intervención en los hechos y su posición en la estructura empresarial.

El apartado 6 del artículo 91 se remite ahora expresamente al artículo 315 de la LEC para los supuestos de interrogatorio de las administraciones o entidades públicas (interrogatorio por escrito).

\subsection{Prueba testifical}

La LRJS pretende evitar que declaren como testigos personas vinculadas a las partes por vínculos de parentesco, análoga afectividad o con interés real en la defensa de los intereses de la posición empresarial por haber participado en esta o por tener procedimientos análogos contra el empresario o contra trabajadores en igual situación. Solo en el caso de que estos testimonios tengan utilidad directa y no se disponga de otros medios de prueba, podrá acordarse esta prueba testifical.

\subsection{Prueba documental y pericial}

Se regula la posibilidad de que, tras la finalización de la vista, el juez solicite de las partes sucintas conclusiones complementarias por escrito respecto de las pruebas documentales y periciales aportadas a los autos cuando estas sean de extraordinario volumen y complejidad, lo que se hará preferiblemente por medios telemáticos y justificando haber enviado copia a la parte contraria. 


\section{Sexto objetivo: cambios en las modalidades procesales}

\subsection{Despido}

Se precisan en la LRJS de forma más exhaustiva los requisitos de la demanda y de la sentencia en relación con los hechos y además:

A) Se clarifica lo que ya venía siendo interpretado por los tribunales: el reconocimiento de improcedencia del despido realizado en la propia carta extintiva o en momento ulterior vincula al empresario y, en consecuencia, le inhabilita para defender en sala las razones del despido y la cuantía ofrecida, sin perjuicio de poder subsanar la cuantía con fundamento en un error material.

B) También se explicitan las consecuencias del error excusable o inexcusable respecto del cálculo de la indemnización, clarificando, a su vez, lo que la doctrina de la Sala de lo Social del Tribunal Supremo ha venido declarando a tales efectos.

C) Se introduce una relevante novedad: se faculta al juez de lo social para imponer una sanción disciplinaria distinta de la del despido en el caso de que los hechos en los que este se fundamentó fueran de menor gravedad y no se apreciara prescripción; en tal caso, el empleador podrá imponer esa sanción en el plazo de caducidad de los 10 días hábiles siguientes a la firmeza de la sentencia y tras la readmisión del trabajador en regular forma. El afectado podrá impugnar dicha sanción en el plazo de 20 días hábiles a través del incidente de ejecución de la sentencia de despido, esto es, no será necesario que el trabajador interponga nueva demanda para impugnar esa nueva sanción disciplinaria, al amparo de lo dispuesto en los artículos 114 y 115 de la LRJS.

D) Por lo que se refiere a los efectos del despido improcedente, también es destacable la modificación del artículo 110 de la derogada LPL:

- La parte que tenga la titularidad de la opción entre la readmisión y la indemnización podrá anticipar su opción expresamente en el acto de juicio para el caso de declaración de improcedencia, sobre la que el juez se pronunciará en la sentencia.

- La parte demandante podrá solicitar, en caso de improcedencia del despido, que se tenga por hecha la opción por la indemnización, en el caso de que constara no realizable la readmisión, lo que el juez podrá acordar en la sentencia que declare extinguida la relación laboral (lo que se lleva a cabo sobre la base del artículo 286 LRJS y ya se recogía en el artículo 284 LPL). 


\subsection{Movilidad geográfica y modificaciones sustanciales de condiciones de trabajo}

Es de destacar la modificación operada en el artículo 138.1, en el sentido de que, aunque no se hayan seguido las formalidades establecidas en los artículos 40 y 41 del ET, la impugnación de dicha medida se realizará de conformidad con lo previsto en el artículo 138 de la LRJS, con sometimiento a su plazo de caducidad - que computará desde la notificación por escrito-, sin perjuicio del plazo de prescripción previsto en el artículo 59.2 del ET. Ello cambia en la LRJS lo que sucedía con anterioridad a esta: se reconducía al procedimiento ordinario la cuestión y se orillaba la modalidad especial de movilidad geográfica y modificación sustancial.

Por otro lado, el apartado 7 del artículo 138 aclara ahora expresamente lo que ya había mantenido la doctrina: en el caso de que la medida se declare ajustada a Derecho, el trabajador tiene la posibilidad de extinguir la relación laboral al amparo de lo previsto en los artículos 40.1 y 41.3 del ET, para lo cual se le concede el plazo de 15 días.

\subsection{Conciliación de la vida personal, familiar y laboral (art. 139 LRJS)}

A) Se posibilita la acumulación de reclamación de daños y perjuicios a dicho procedimiento para el caso de que el empresario no hubiera accedido a la petición del trabajador, aun siquiera de forma provisional.

B) Las partes deberán llevar a los actos de conciliación y juicio sus alternativas y propuestas de concreción de la medida.

C) Se potencia la intervención de los órganos paritarios y de los de seguimiento de los planes de igualdad en la empresa.

D) Este procedimiento se hace extensivo a las reclamaciones de las mujeres víctimas de violencia de género, a la reducción de jornada con reducción proporcional del salario, a la reordenación del horario, a la aplicación del horario flexible y a cuantas cuestiones se refieran a la ordenación del tiempo de trabajo en la empresa.

\subsection{El proceso de conflicto colectivo}

Esta modalidad es ahora regulada en los artículos 153 al 162 de la LRJS. La nueva regulación establece lo siguiente: 
A) En relación con su elemento subjetivo, procederá ahora esta modalidad también en el caso de un grupo genérico de trabajadores susceptible de determinación individual, lo que no debe confundirse con una demanda plural, que deberá tramitarse por el procedimiento ordinario.

B) Procede esta modalidad para discutir sobre la aplicación o interpretación de los acuerdos de interés profesional de los TRADE.

C) Respecto de la legitimación activa, se incluye expresamente a las asociaciones y los sindicatos representativos de los TRADE y a las administraciones públicas empleadoras y a los órganos de representación de su personal laboral.

D) Por lo que se refiere a la demanda, si la pretensión es de condena y no meramente declarativa, se deberán especificar los requisitos para una ulterior individualización de los afectados en aras de la ejecución de sentencia. Igual concreción se exige para la sentencia en el artículo 160.3 de la LRJS en el caso de que esta sea susceptible de ejecución individual.

E) Se establece el efecto de cosa juzgada de la sentencia tanto en el orden social como en el contencioso-administrativo. Con relación a la excepción de cosa juzgada, se viene distinguiendo doctrinal, legal y judicialmente desde hace décadas entre cosa juzgada formal (que es el efecto propio de las resoluciones irrecurribles que se da dentro del mismo proceso - art. 207 LEC_) y cosa juzgada material (que viene referida, en general, a los efectos de la regla general de inmutabilidad del fallo que provoca la cosa juzgada formal en otro proceso distinto). Esas precisiones se contienen ahora principalmente en el artículo 222 LEC, según el cual la cosa juzgada material (que es la que nos interesará de ahora en adelante) puede producir dos tipos de efectos: el negativo (o excluyente) y el positivo (o prejudicial).

El efecto negativo responde básicamente al principio non bis in ídem e impone al juzgador la obligación de poner fin (es decir, sin entrar en el fondo del asunto) a un proceso que se refiera al mismo objeto que otro que concluyó con sentencia firme (art. 222.1 LEC), proscribiendo así toda decisión judicial futura entre las mismas partes referida al mismo objeto o pretensión procesal, tanto si se pretende el mismo como otro resultado que trate de corregir lo resuelto en un pleito anterior. El efecto positivo de la cosa juzgada material, por su parte, impone al juzgador la obligación de estar a lo resuelto en un proceso anterior que concluyó con sentencia firme (art. 222.4 LEC). De este modo, para que se produzca el efecto positivo o prejudicial de cosa juzgada resulta presupuesto necesario que lo decidido en el primer proceso actúe en el segundo como elemento condicionante, de forma que la primera sentencia no excluye el segundo pronunciamiento, pero lo condiciona, vinculándolo a lo ya fallado; la función positiva de la cosa juzgada no impide, pues, que se dicte sentencia en el segundo juicio, pero vincula al tribunal 
del proceso posterior $y$, por lo tanto, le obliga a seguir y aplicar los mandatos y criterios establecidos por la sentencia firme anterior o, enunciado en sentido negativo, prohíbe que pueda decidirse en un segundo proceso un tema o punto litigioso de manera distinta de como ya ha sido resuelto en sentencia firme en otro proceso precedente.

\subsection{Tutela de derechos fundamentales}

Esta modalidad se amplía a todos los derechos y libertades constitucionales objeto de amparo (libertad sindical, huelga u otros derechos fundamentales y libertades públicas, incluida la prohibición de tratamiento discriminatorio y del acoso).

Se deja a elección del trabajador dirigir la demanda contra el tercero vinculado al empresario que haya sido causante de la lesión, salvo que la sentencia pudiera afectarle directamente, evitándose, por lo tanto, la exigencia forzada de un litisconsorcio pasivo necesario.

Se regula de forma más exhaustiva la pretensión indemnizatoria, que no será compatible con la ejercitada en un procedimiento penal. Asimismo, se arbitran medidas cautelares específicas en función del derecho fundamental presuntamente vulnerado. Finalmente, el artículo 183.2 de la LRJS establece la facultad del juzgador para fijar prudencialmente la indemnización en favor de la víctima en el caso de que la prueba de su importe exacto resulte demasiado difícil o costosa.

Un problema se plantea en este punto: la tutela de los derechos de libertad sindical y de huelga de los funcionarios públicos, así como del personal estatutario de los servicios de se sustancian, como antes de la LRJS, ante la jurisdicción contencioso-administrativa.

\subsection{Impugnación de altas médicas}

La LRJS establece un régimen especial para la impugnación de las altas médicas, esto es, las altas cursadas por el INSS o mutuas de procesos de incapacidad temporal. Se exige reclamación escrita previa, salvo cuando se impugnen altas médicas emitidas por el INSS al agotarse el plazo máximo de duración de trescientos sesenta y cinco días de la prestación de incapacidad temporal. En los demás supuestos se mantiene la exigencia de la presentación de la reclamación previa, comprendiendo tanto los casos en que el alta médica se acuerda con anterioridad a agotarse el plazo de trescientos sesenta y cinco días como aquellos en que se deciden después de haberse prorrogado la incapacidad temporal. 
El plazo para la presentación de la reclamación previa es mucho más breve que el general, para otros procesos (por ejemplo, para pedir una incapacidad permanente al INSS), de treinta días: once días desde la notificación de la resolución de alta médica (art. 71.2 LRJS). El plazo para contestar la reclamación es de siete días, entendiéndose desestimada una vez transcurrido dicho plazo (es lo que se llama silencio negativo). El plazo para interponer la demanda pasa de treinta días (LPL) a veinte días (LRJS), en línea con la intención del legislador de agilizar el procedimiento.

Otras especialidades en el procedimiento de impugnación de las altas médicas son las siguientes (art. 140.3 LRJS): a) agosto es hábil; b) se dirige la demanda frente al INSS y, en su caso, frente a la colaboradora en la gestión de la incapacidad temporal (mutua); c) no se exige demandar al servicio público de salud, salvo que sus servicios médicos hayan emitido el alta médica (en Cataluña, ICAM); d) no se demanda tampoco a la empresa; e) se prohíbe la acumulación de acciones, ni siquiera la reclamación de diferencias en el abono del subsidio de la incapacidad temporal; y f) contra la sentencia que se dicte no cabe recurso de suplicación, siendo sus efectos la de declarar procedente o indebida el alta médica impugnada, sin condicionar otros procesos, sea por la contingencia, la base reguladora, las prestaciones derivadas o cualquier otro extremo. Si la sentencia estima indebida el alta médica, condenará a la reposición en la prestación que se viniera percibiendo, en tanto no concurra causa de extinción de esta por el transcurso del tiempo por el que hubiese sido reconocida o por otra causa legal de extinción.

\subsection{La impugnación de los convenios y pactos colectivos}

Según reconoce expresamente la nueva Ley, la jurisdicción contencioso-administrativa conoce también de los litigios sobre los pactos o acuerdos concertados por las administraciones públicas con arreglo al Estatuto Básico del Empleado Público «que sean de aplicación al personal funcionario o estatutario de los servicios de salud, ya sea de manera exclusiva o conjunta con el personal laboral; y sobre la composición de las Mesas de negociación sobre las condiciones de trabajo comunes al personal de relación administrativa y laboral». La jurisdicción social, por su parte, conoce de los litigios sobre «impugnación de convenios colectivos y acuerdos, cualquiera que sea su eficacia, incluidos los concertados por las Administraciones públicas», pero «cuando sean de aplicación exclusiva a personal laboral», así como sobre «impugnación de laudos arbitrales de naturaleza social incluidos los dictados en sustitución de la negociación colectiva, en conflictos colectivos, en procedimientos de resolución de controversias y en procedimientos de consulta 
en movilidad geográfica, modificaciones colectivas de condiciones de trabajo y despidos colectivos. De haberse dictado respecto de las Administraciones públicas, cuando dichos laudos afecten en exclusiva al personal laboral».

\section{Séptimo objetivo: cambios en los medios de impugnación}

\subsection{Recurso de suplicación}

A fin de adaptar el acceso a este recurso a las nuevas materias asumidas por la jurisdicción social, se actualizan las materias en las que cabe acudir a la suplicación. Igualmente, se generaliza el acceso a la suplicación en supuestos de terminación anticipada del procedimiento (desistimiento por incomparecencia del demandante, por ejemplo), situación que, al carecer hasta ahora de recurso, había dado lugar a un excesivo número de recursos de amparo.

Se actualiza (incrementándose) la cuantía exigida para acceder a la suplicación, que pasa de 1.800 euros (cuantía de la derogada LPL) a 3.000 euros. Es importante reflejo de la voluntad del legislador de reducir el número de recursos en cantidades «pequeñas», con un matiz práctico: si reclaman varios trabajadores y ninguno de ellos alcanza los 3.000 euros por separado, no se pueden «sumar» las cantidades para tratar de «colar» el recurso, aunque si uno de ellos supera individualmente en su reclamación los 3.000 euros, dicho recurso se puede presentar.

Es relevante la modificación operada respecto del acceso al recurso de suplicación en materia de clasificación profesional y derechos de conciliación de la vida personal, familiar y laboral. Se admite ahora el recurso de suplicación, siempre que a tales procedimientos se haya acumulado una reclamación de cantidad (diferencias salariales o de daños y perjuicios) no inferior a 3.000 euros.

Dentro de las medidas de modernización del proceso laboral, como fundamento de la reforma operada se alude expresamente al expediente judicial electrónico: se establece la posibilidad de dar acceso a las actuaciones de forma telemática a los efectos de instrucción e interposición del recurso $y$, de ser posible, realizar esto de forma simultánea a todas las partes recurrentes dentro de un plazo común para todas ellas. En la práctica, se trata todavía de un tema bastante inédito.

Otra novedad destacable es la impugnación eventual de la sentencia por parte de la parte recurrida en el trámite de oposición al recurso. Dicha modificación implica que el recurrido podrá realizar alegaciones sobre la admisibilidad del recurso, así como proponer rectificaciones fácticas y motivos de oposición a la sen- 
tencia de forma subsidiaria, para lo que deberá cumplir con los requisitos que se establecen en la LRJS para fundamentar los motivos de suplicación.

\subsection{Recurso de casación para la unificación de doctrina}

Se amplían las posibilidades de acceso al recurso de casación para unificación de doctrina (RCUD), toda vez que se establece de forma explícita la posibilidad de alegar como doctrina de contraste sentencias del Tribunal Constitucional y sentencias dictadas por los órganos jurisdiccionales instituidos en los tratados $y$ acuerdos internacionales en materia de derechos humanos y libertades fundamentales ratificados por España, así como la doctrina de las sentencias del Tribunal de Justicia de la Unión Europea en interpretación del derecho comunitario.

También se amplía el ámbito del RCUD, con una nueva modalidad que puede interponer el Ministerio Fiscal en defensa de la legalidad y sin necesidad de que concurra el presupuesto de contradicción de sentencias.

Igualmente, se alude al acceso telemático a las actuaciones que obren en la Sala de lo Social del correspondiente Tribunal Superior de Justicia, a los efectos de preparar el RCUD, se reduce de 20 a 15 días el plazo para la interposición del RCUD y se clarifican ahora en la norma, de conformidad con la jurisprudencia existente en la materia, los requisitos de la contradicción y de las sentencias de contraste.

\subsection{Cuantía de los depósitos, exención de tasas judiciales y costas en los recursos}

La cuantía de los depósitos para el acceso a los recursos se incrementa: 300 euros para el recurso de suplicación (antes, 150 euros) y 600 euros para el de casación (antes, 300 euros). Se supone que ello desincentiva a quien quiera recurrir y no tenga demasiados motivos para ello (para no saturar las salas de lo social de los TSJ) y además no goce del beneficio de justicia gratuita (es decir, las empresas), pero está por ver que dicho objetivo se cumpla. Al menos, eso sí y en términos de abaratamiento de costes, el proceso laboral, a diferencia de lo que sucede en el proceso judicial civil y en el contencioso, no incluye «tasas» por la presentación de la demanda o interposición de recursos.

En cuanto a la imposición de costas, la LRJS incrementa el tope máximo de los honorarios de abogados o graduados sociales colegiados, en su caso, hasta 
1.200 euros en el recurso de suplicación y hasta 1.800 euros en el recurso de casación (antes, 600 y 900 euros, respectivamente).

\subsection{Otros recursos}

El recurso de reposición (que se presenta ante el mismo juez que ha dictado una resolución y que se resuelve por dicho juez) deberá interponerse en el plazo de tres días contra las resoluciones procesales dictadas en procedimientos seguidos ante un órgano unipersonal (JS) y de cinco días contra las resoluciones dictadas en procedimientos seguidos ante un órgano colegiado (TSJ, AN o TS), e igualmente la impugnación de dicho recurso deberá efectuarse, en su caso, en el plazo común de tres o cinco días, respectivamente.

Además, la Ley 37/2011, de 10 de octubre, de medidas de agilización procesal (BOE de 11 de octubre de 2011), incide en esta materia, dada la supletoriedad de la LEC, y modifica singularmente la sustanciación y decisión del recurso de queja (contra la inadmisión de un recurso de suplicación), de modo que ahora el recurso de queja es directo ( $\sin$ necesidad de reposición previa ante el JS) ante la Sala de lo Social del TSJ contra el auto que deniega la tramitación del recurso de suplicación (o ante el TS si es el TSJ el que deniega un recurso de casación).

Finalmente, la LRJS crea un nuevo recurso de casación contra las sentencias y otras resoluciones dictadas en única instancia por las salas de lo social de los tribunales superiores de justicia y por la Sala de lo Social de la Audiencia Nacional (por ejemplo, sentencias dictadas en procesos de ERE con despido colectivo). Dicho recurso se basa en motivos tasados (abuso, exceso o defecto en el ejercicio de la jurisdicción; incompetencia o inadecuación de procedimiento; quebrantamiento de las formas esenciales del juicio por infracción de las normas reguladoras de la sentencia o de las que rigen los actos y las garantías procesales, siempre que, en este último caso, se haya producido indefensión para la parte; error en la apreciación de la prueba basado en documentos que obren en autos que demuestren la equivocación del juzgador, sin resultar contradichos por otros elementos probatorios; infracción de las normas del ordenamiento jurídico o de la jurisprudencia que fueren aplicables para resolver las cuestiones objeto de debate). 


\section{Octavo objetivo: cambios en la ejecución de sentencias}

De interés resulta la previsión de la LRJS de alcanzar acuerdos transaccionales en ejecución, lo que resultaba prohibido con anterioridad según lo establecido en el artículo 245 de la LPL. Ahora, el artículo 246 de la LRJS prevé tal posibilidad, dentro de los límites legalmente establecidos, debiendo homologarse dicha transacción por auto judicial. Me parece una medida de sumo interés por cuanto, por ejemplo en caso de deuda dineraria, se pueden pactar entre las partes los plazos de pago de esta sin necesidad de acudir a embargos o a rastrear cuentas corrientes o bienes del «ejecutado», lo que, sin duda, agiliza el proceso de ejecución.

Novedad, también, es la nueva regulación de la oposición a la ejecución. En concreto, se indica en la LRJS que, contra el auto que despacha la ejecución, cabe recurso de reposición fundado en el cumplimiento o incumplimiento de los presupuestos y requisitos procesales, y dentro de este, podrá deducirse la oposición, basada en el pago, prescripción u otros hechos impeditivos, extintivos o excluyentes de la responsabilidad, siempre que bubieran acaecido con posterioridad a la constitución del título ejecutivo, exceptuándose expresamente la compensación. Esta regulación, sin embargo, no contribuye a dar celeridad al procedimiento y sí a aumentar los supuestos en los que cabe recurso de suplicación contra el auto resolutorio de la reposición. Del recurso de reposición se dará traslado a la parte contraria en el plazo de tres días - y no de cinco como en la anterior regulación-, salvo que el juez, «en atención a las cuestiones planteadas o por afectar a hechos necesitados de prueba, acuerde seguir el trámite incidental del art. 238 LRJS», lo que es lo más habitual en la práctica (reconversión del recurso en dicho incidente).

El artículo 240.2 LRJS regula expresamente la modificación o cambio de las partes en la ejecución, siempre que dicho cambio se fundamente en circunstancias sobrevenidas y posteriores a la constitución del título ejecutivo. Sería el caso de una empresa condenada en una sentencia que después es sustituida por otra (subrogación) que es su continuadora encubierta: la ejecución se puede extender a esta «nueva» empresa. Se regula expresamente, así, la sucesión o cambio de partes en la ejecución, conforme a la jurisprudencia constitucional y la ordinaria (arts. 238 y 240 LRJS). La ampliación subjetiva de la ejecución (sucesión, grupos) requerirá estar fundada en hechos posteriores a la constitución del título, disponiéndose, conforme a la jurisprudencia social del TS, que la modificación o cambio de partes en la ejecución debe efectuarse, de mediar oposición y ser necesaria prueba, a través del trámite incidental previsto en el artículo 238, de modo que para que pueda declararse es requisito indispensable que el cambio 
sustantivo en que se funde, basado en hechos o circunstancias juridicas sobrevenidos, se bubiere producido con posterioridad a la constitución del título objeto de ejecución (art. 240.2 LRJS).

Otra modificación relevante ha sido introducida en la ejecución de sentencias firmes de despido: se prevé la posibilidad de que, en las sentencias firmes de despidos nulos por acoso de cualquier tipo, el trabajador despedido pueda optar por la extinción del contrato con derecho a la indemnización y a los salarios de tramitación, sin que sea obligatoria en tal caso la readmisión.

Finalmente, si el empresario interpone recurso de suplicación contra la sentencia que acuerde la extinción del artículo 50 ET, se establece la opción a favor del trabajador (que deberá efectuar en el plazo de cinco días desde la notificación de que la empresa ha recurrido) entre continuar prestando servicios o cesar en la prestación en cumplimiento de la sentencia, quedando, desde el momento en que la ejercite en este último sentido, en situación de desempleo involuntario. Este derecho de opción supone un avance importante porque puede haber casos en que para el trabajador sea muy gravoso (por ejemplo, en los casos de acoso laboral, para la dignidad de su persona u otras circunstancias) seguir prestando servicios mientras se sustancia el recurso. El acierto aquí es que la LRJS incorpora lo que la STC 225/2002 denominó «autotutela inmediata» al amparar la extinción indemnizada, ex artículo 50 del Estatuto de los Trabajadores, de un periodista que, en el momento de interponer la demanda, había ya cesado voluntariamente. De ser revocada la sentencia, el empresario deberá, dentro del plazo de diez días a contar desde la notificación de la sentencia de la Sala, comunicar al trabajador la fecha de su reincorporación, que deberá efectuar en un plazo no superior a tres días desde el siguiente al del requerimiento. De no incorporarse el trabajador en plazo, quedará extinguida definitivamente la relación laboral.

\section{A modo de cierre: el incremento de los litigios laborales y de seguridad social durante 2012}

A modo de cierre, no puedo sustraerme a la necesidad de comentar cómo se vive, desde la jurisdicción social, el efecto de la reforma en términos de litigiosidad. La crisis económica, desde luego, está provocando un incremento considerable de litigiosidad que no encierra controversia jurídica alguna, sino que trae causa en el incumplimiento de obligaciones empresariales por dificultades de tesorería, de forma que los jueces venimos actuando como una especie de «notarios» de deudas que resulten acreditadas. 
Por su parte, la «judicialización» de los expedientes colectivos de suspensión, reducción de jornada y/o extinción colectiva es evidente, siendo tal la intención del legislador al derogar la necesidad de autorización administrativa previa. Esa supresión autorizatoria se enmarca, sin duda, en la onda de las normas europeas y de las experiencias de otros países (junto con Portugal, España era el único país que aún conservaba ese requisito), pero ello no oculta el brutal incremento de tales ERE (ya no necesitados de autorización administrativa, insisto, salvo en los casos de «fuerza mayor») desde la reforma. No es un efecto perverso o reflejo o una lectura interesada, es, simplemente, una realidad contrastada y contrastable.

El número de despidos y de empresas en concurso (que comparecen mediante administrador concursal cuando este puede asistir a los juicios laborales) se ha elevado exponencialmente de modo importantísimo; las reclamaciones por desempleo o de prestaciones de incapacidad se han duplicado (efecto de la crisis, sin duda); el número de asuntos en los que la empresa no comparece (porque ha desaparecido y ha debido ser citada por edictos, o por otras razones) ha aumentado vertiginosamente; $y$, en fin, los autos de insolvencia se multiplican ante los problemas ya indicados de tesorería de las empresas. A todo ello se suma la escasez de medios (humanos y materiales) en los juzgados, la saturación por la entrada abrumadora de trabajo, la mayor dificultad técnica de muchos procedimientos (por ejemplo, por la introducción de prueba documental y pericial de miles de folios), el mal clima generado por los recortes a los empleados públicos (incluido el anuncio de una paga extra de Navidad que no va a ser abonada — por cierto, el Tribunal Constitucional de Portugal, en Sentencia núm. 353/2012, ha declarado inconstitucional la supresión de pagas extraordinarias para empleados públicos en dicho país por entender que no se puede justificar una medida de reducción de retribuciones dirigida solo a los trabajadores públicos, excluyendo al sector privado de la economía, por considerarla una medida discriminatoria-), etc., lo que no impide que, con voluntarismo y tesón, miles de sentencias se dicten a diario en los juzgados de lo social de toda España, incluidos temas de las «nuevas competencias». Este es, en fin, el panorama en el que se mueve la nueva LRJS en la práctica cotidiana. 